\title{
Psicólogos em Formação: Vivências e Demandas em Plantão Psicológico
}

Graduating psychologists:

Experiences and requirements in psychological duty
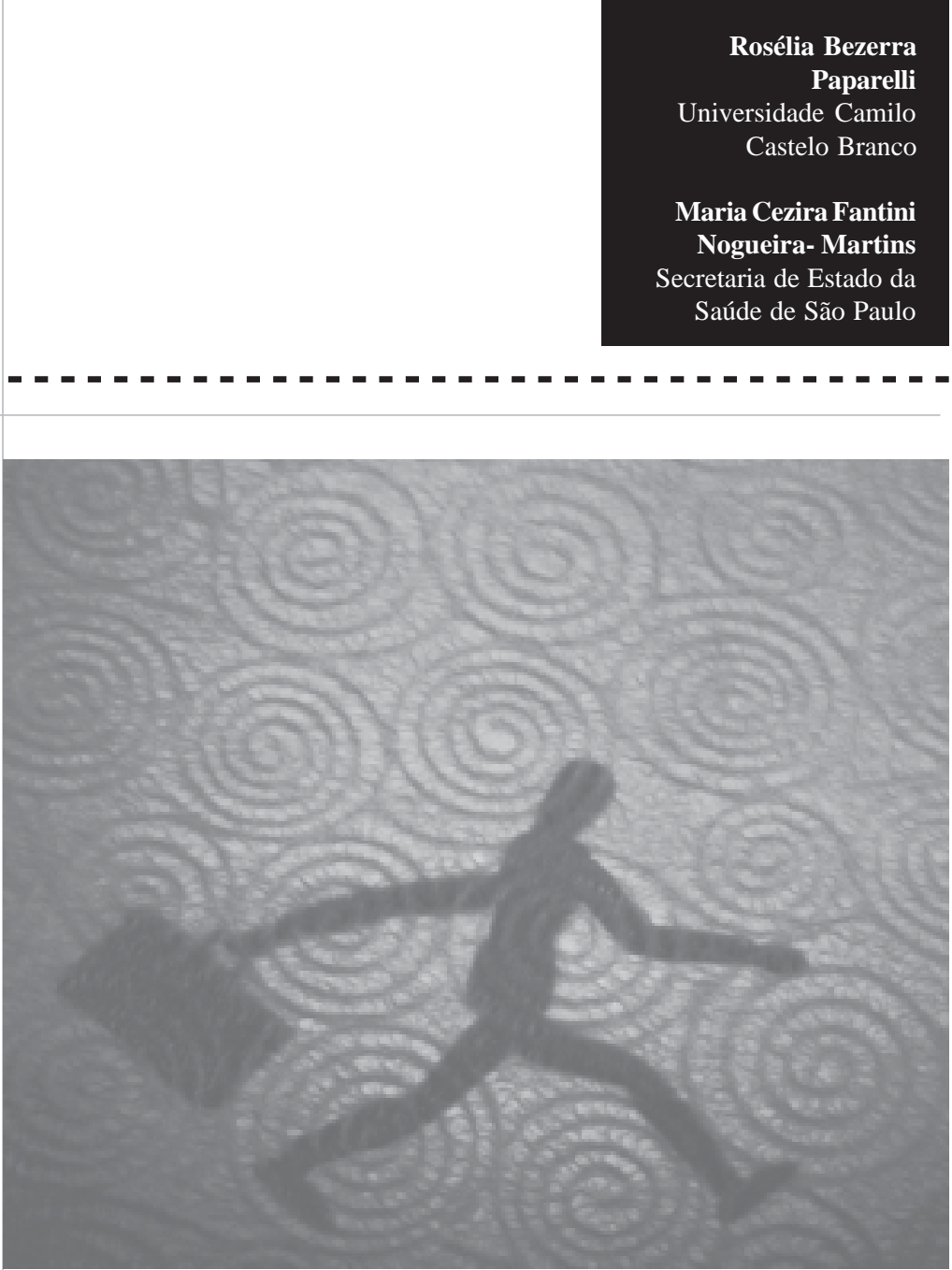


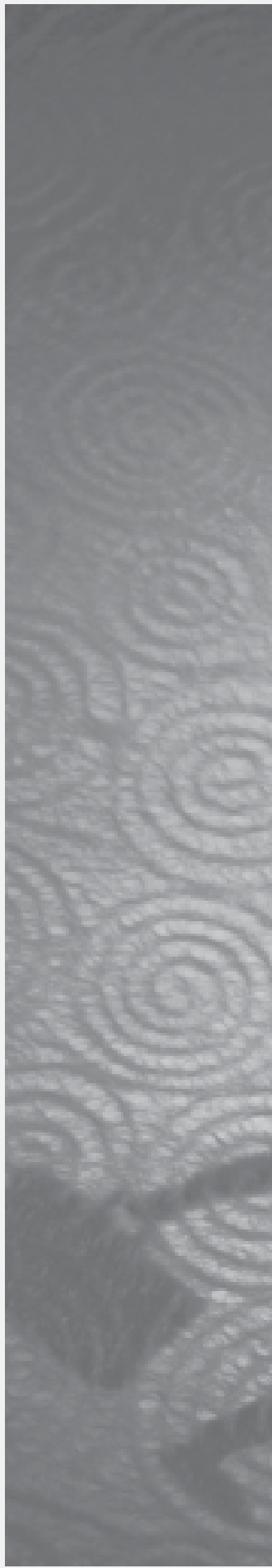

Resumo: Este trabalho buscou compreender e refletir sobre a formação do psicólogo. Utilizando a pesquisa qualitativa, objetivou-se conhecer o impacto dessa realidade nas vivências do aluno, enquanto plantonista, e verificar se essa inserção favoreceria a instalação de uma consciência crítica de nossa realidade social. Utilizou-se a técnica de grupo focal, numa amostra de trinta e oito alunos, cujo material foi analisado em análise temática. O recorte foi um estágio desenvolvido em plantão psicológico, realizado numa clínica-escola de uma universidade particular da zona leste de São Paulo, cujo atendimento se aproxima das necessidades da comunidade. Os resultados mostram que a inserção do graduando no plantão psicológico trouxe desilusões e rupturas das certezas instituídas nos fazeres e saberes do trabalho psicológico, o que contribuiu para uma nova construção na maneira de olhar para antigas questões e legitimar a necessidade de revisão e questionamento de nossas práticas cotidianas, contextualizadas na realidade de nossas populações.

Palavras-chave: recursos humanos em saúde, Psicologia aplicada/ética, serviços comunitários de saúde mental, prática profissional.

Abstract: The objective of this work is the reflection and the understanding on the preparation of a psychologist and, according to the qualitative approach of the research, the comprehesion of the impact of this reality in the student's life experience, while on duty, in the 5th year of their Psychology courses, and the verification if this insertion would favor the installation of a critical awareness of our social reality. The focusing group technique was used in a sample of 38 students. The obtained material was submitted to thematic analysis. A training program, developed during psychological duties, was taken as a model and performed in a school clinic of a private university in the east side of São Paulo, whose attendance is focused on the needs of the community. The results show that the insertion of the graduating student on psychological attendance made it possible to dissolve the uncertainty instituted in the psychological knowledge and practices, thus contributing to a new construction in the way we consider the old questions, legitimating the need for a revision and questioning of the daily practices that are contextualized in the reality of our population .

Key words: health manpower, Psychology applied/ethics, community mental health services, professional practice. 
De maneira resumida, o plantão se caracteriza por três pontos de vista: o da instituição, da qual se exige a sistematização dos serviços, com a organização e o planejamento do espaço físico, os recursos disponíveis (humanos ou materiais, rede de apoio externo e outros); o do profissional, cuja exigência se refere à "disponibilidade" ao novo, ao não planejado, ao inusitado, à possibilidade de acolher a demanda daquele que o procura, e o do cliente, que

constitui uma referência, um porto seguro para a sua necessidade'. Mahfoud
A formação do psicólogo, desde a regulamentação da profissão, esteve muito aquém das necessidades sociais de nossas populações, deflagrando, no meio social, a indefinição da verdadeira utilidade da profissão e transformando o psicólogo em um profissional que, muitas vezes, é tomado como prescindível. Assim, reconhece-se, atualmente, a necessidade de um profissional sintonizado com as demandas sociais. Embora esse seja um fato admitido pelo agente formador, percebemos o quanto é difícil modificar o panorama da formação, pois sobre ela repousa uma complexa série de fatores que inviabilizam uma tomada de posição éticopolítica favorecedora de mudanças qualitativas. Se essa é uma verdade que consegue ficar apartada no sistema educativo-formativo, o mesmo já não se dá no meio profissional, quando observamos a pressão exercida sobre os profissionais solicitados a responder a demandas que o ensino tecnicista não consegue abarcar.

As clínicas-escola são o ponto de intersecção entre a formação e o exercício profissional. O tema do atendimento em clínicas-escola, em função de sua relevância e representatividade social na área da saúde, é, a partir da década de 1980, muito enfatizado por autores brasileiros, independentemente da filiação teórica, justamente por representar a interface entre o "produtor" do conhecimento científico, a demanda social e o compromisso com a formação; a pressão da realidade social exige ajustes criativos dos agentes formadores que, como acadêmicos, se encontram em situação diferenciada e privilegiada, por se manterem em um esbarrar constante com a população que desses serviços se utiliza, o que mobiliza sua inquietude enquanto pesquisadores, impulsionando-os a refletir sobre os aspectos da realidade que se incorporam às necessidades cotidianas da formação e que não podem ser dela apartadas (Ancona-Lopes, 1981; Ancona-Lopes, 1986; Macedo, 1986;
Schmidt, 1992; Silva, 1992; Ancona-Lopes, 1995; Yehia, 1996a; Yehia, 1996b; Cury e Di Nucci, 1998).

Assim, o confronto com a realidade instaura, nas clínicas-escola, um novo dilema: a prestação de serviços realmente efetivos (Castro, 1998). Essa demanda às clínicas-escola desencadeia e determina, para elas, uma nova identidade, muito mais ambígua, em que não parece mais ser possível priorizar uma função "formativa" em detrimento de sua outra função - o “atendimento comunitário”.

O plantão psicológico, como forma de atividade das clínicas-escola, tem se mostrado uma tentativa de integração dessas duas necessidades: a formação e o atendimento à população. Mahfoud (1987) define plantão como "...certo tipo de serviço, exercido por profissionais que se mantêm à disposição de quaisquer pessoas que deles necessitem, em períodos de tempo previamente determinados e ininterruptos" (Mahfoud, 1987, p.75). Segundo o autor, a intervenção psicológica em "plantão" apresenta características específicas para cada um dos envolvidos e, por isso, é citada como "a vivência de um desafio", dada a sua complexidade. De maneira resumida, o plantão se caracteriza por três pontos de vista: o da instituição, da qual se exige a sistematização dos serviços, com a organização e o planejamento do espaço físico, os recursos disponíveis (humanos ou materiais, rede de apoio externo e outros); o do profissional, cuja exigência se refere à "disponibilidade" ao novo, ao não planejado, ao inusitado, à possibilidade de acolher a demanda daquele que o procura, e o do cliente, que constitui uma referência, um porto seguro para a sua necessidade (Mahfoud, 1987).

Os trabalhos publicados que referenciam o desenvolvimento da atividade em plantão psicológico são, via de regra, realizados na abordagem centrada no cliente (Mahfoud, 1987; Cury e Di Nucci, 1998; Cury, 1999; 
Morato, 1999). Contudo, é um tipo de atividade que pode também ser promovido em outras abordagens. O ponto comum dessa vivência em plantão psicológico é que esse é um trabalho que requer, de seu executante, independentemente da abordagem, uma tomada de posição - pessoal, ética, política, social, profissional. Evidentemente, essa condição também se circunscreve no desenvolvimento de outras atividades profissionais do psicólogo e não só no plantão, mas o plantão, de alguma forma, exige a tomada de postura imediata.

O serviço de plantão psicológico analisado neste estudo iniciou suas atividades em 1997, na Faculdade de Psicologia de uma instituição de ensino superior privada, tomando como referência o modelo de plantão psicológico realizado no Instituto de Psicologia da Universidade de São Paulo - IPUSP, que se pautava na abordagem centrada no cliente. A partir desse modelo inicial, o serviço de plantão psicológico aqui estudado foi se modificando, em decorrência das características da região e da especificidade de sua atuação, e passou a agregar duas abordagens teóricas: comportamental cognitiva e psicanalítica psicodinâmica.

Fundamentados pelas necessidades de uma realidade socioeconômica e cultural, os responsáveis por esse serviço foram chamados a responder por alternativas diferentes de atendimento, sem, contudo, abdicar de sua responsabilidade ética, implicada na formação. Assim, propuseram a retomada das teorias e práticas desenvolvidas, para destas se extrair uma possibilidade de acolher o processo emergente (Andrade, 1996), isto é, acolher o emergente, o diferente, o excluído, possibilitando, assim, a reflexão, os ajustes e as transformações necessárias nas formas habituais de atendimento.

A falta de recursos em saúde, característica da zona onde se insere a Universidade, faz deste plantão psicológico uma referência regional, e, em decorrência de suas características, o trabalho volta-se principalmente para pacientes com histórias de situações críticas e traumáticas, que pressupõem uma ação interventiva imediata. O aluno plantonista tem contato, em sua formação teórica, com conteúdos que têm como objetivo possibilitar que ele possa atuar, de modo interventivo, nos momentos de crise que, segundo Bellak e Small (1980), são as situações críticas que põem à prova os recursos e forças dos indivíduos e ameaçam sua integridade, impondo condições além da possibilidade adaptativa da pessoa.

Os plantões ocorrem semanalmente, quando um grupo de doze alunos é diretamente acompanhado pelo professor supervisor responsável. Esse supervisor permanece na companhia de seu grupo, durante o período de plantão (três horas). Sua função é, durante a ocorrência do plantão, subsidiar, orientar, apoiar, esclarecer, discutir e, às vezes, assumir o próprio atendimento, com ou sem o aluno plantonista.

O primeiro atendimento do ano é realizado pelo supervisor, enquanto seu grupo de alunos o observa na sala de espelho.

\section{$\mathrm{O}$ atendimento no serviço ocorre em três fases:}

Primeira sessão - Acolhimento da demanda, numa entrevista inicial, para detecção da queixa e dos elementos trazidos pelo paciente.

Acompanhamento - Processo de intervenções de tempo limitado, com um limite máximo de dez sessões.

- Desfecho - Momento de encerramento do processo, que poderá resultar na alta do processo terapêutico e/ou no encaminhamento a outras instâncias internas ou externas. 
Um número representativo de clientes comparece com queixas que não podem ser supridas pelo serviço em função de suas limitações; assim, nem todos passam pelas três fases descritas. Entretanto, qualquer solicitante é atendido; promovem-se orientações, encaminhamentos, esclarecimentos sobre a melhor possibilidade de ajuda bem como intervenções indiretas, junto a familiares e/ ou instituições.

Os objetivos do serviço de plantão psicológico são:

- Acolher a demanda do indivíduo que sofre, a partir da utilização de métodos e técnicas de tempo limitado, em conformidade com a abordagem teórica, tendo como alvo o indivíduo com problemas e o nãoproblemático (Mahfoud, 1987). Essa demanda ampliada envolve as situações críticas, como propõem Bellak e Small (1980): as “crises evolutivas” e as “crises traumáticas”;

Desenvolver o trabalho pela compreensão da maneira como o problema atual afeta a vida do indivíduo, buscando elementos que forneçam uma nova perspectiva de entendimento e ampliem as alternativas desse indivíduo para lidar com suas próprias questões.

Os objetivos pedagógicos do plantão psicológico são:

Aproximar o aluno de sua realidade social e das necessidades de sua comunidade;

- Desenvolver a postura de psicólogo e a capacidade de disponibilidade terapêutica, através do acolhimento da demanda;

- Promover a autonomia e o raciocínio clínico do aluno, ampliando sua compreensão acerca da diversidade de demanda que desse serviço advém.

\section{A pesquisa realizada}

Considerando a importância do plantão psicológico na formação em graduação, constituiu-se uma pesquisa que teve como objetivos: a) compreender como o aluno em formação percebe, explica e representa o atendimento psicológico prestado na clínicaescola à sua comunidade por meio de um serviço de plantão psicológico e b) o quanto essa atividade favorece a instalação de uma consciência crítica de nossa realidade social e promove a reflexão sobre a prática da Psicologia.

Para tanto, foi utilizada a metodologia qualitativa de pesquisa, que consideramos apropriada para a compreensão e a interpretação do fenômeno estudado, na medida em que os fenômenos vividos, partilhados e vivenciados pelo ser humano sofrem uma influência direta de suas crenças, percepções, sentimentos e valores inseridos e singularizados na subjetividade de suas respostas (Nogueira-Martins e Bógus, 2004). A pesquisa foi realizada na Universidade já mencionada ${ }^{1}$.

O campo de pesquisa foi o serviço de plantão psicológico de uma instituição privada de ensino superior, localizada na cidade de São Paulo. A técnica escolhida foi a do grupo focal (Nogueira-Martins e Bógus, 2004), por permitir a obtenção de dados a partir de discussões planejadas, com a expressão das percepções, crenças, valores, atitudes e representações sociais sobre uma questão específica, em um ambiente permissivo e não-constrangedor.

A condução do grupo esteve a cargo da primeira autora deste trabalho, que contou com o auxílio de uma observadora-relatora. Foi utilizado um roteiro de perguntas, que não foi aplicado rigidamente e serviu de guia para a pesquisadora. O roteiro foi constituído pelas seguintes questões: foi analisado e aprovado pelo Comitê de Ética em Pesquisa da Universidade. 
Qual a expectativa que você pôde perceber quanto à clientela que comparece ao serviço de plantão psicológico?

Em sua opinião, que necessidades essa clientela expressa, em seu pedido de ajuda psicológica, quando se utiliza do plantão psicológico?

Na condição de psicólogo plantonista, sentiu dificuldades para atuar? Quais dificuldades?

Nessa condição, quais foram os aspectos que facilitaram e contribuíram para sua inserção nesse trabalho?

- A vivência do papel de psicólogo plantonista no serviço de plantão psicológico propiciou mudanças na sua maneira de ver o trabalho do psicólogo?

- A partir de sua vivência e experiência, como você compreende a saúde mental, dentro da saúde pública?

O material obtido nos grupos focais foi gravado e posteriormente transcrito. Para salvaguardar a identidade dos entrevistados, foram utilizados codinomes de flores, cuja distribuição somente a pesquisadora conhece.

Os participantes dos grupos focais foram alunos que, no $9^{\circ}$ e $10^{\circ}$ semestres do curso de Psicologia, realizaram o serviço de plantão psicológico como estágio curricular e sob supervisão. Foi adotado, como critério de exclusão, a reprovação e/ou desistência do aluno em um dos semestres referidos. De um total geral de quarenta e seis alunos, foram convidados inicialmente quarenta e cinco, já que, no grupo, houve uma reprovação. Desse total, duas pessoas não aceitaram o convite por motivos pessoais e profissionais, três não responderam a qualquer solicitação, e uma pessoa não conseguiu compatibilizar seu horário com os demais participantes. Assim, a amostra ficou constituída por um total de trinta e oito ex-alunos, permitindo a montagem de três grupos, seguindo a preferência horária dos participantes. A organização e a distribuição dos ex-alunos para os grupos focais ocorreram da seguinte forma:

Grupo focal 01 - 12 convidados, 07 participantes e 05 abstenções;

Grupo focal 02 - 14 convidados, 10 participantes e 04 abstenções;

Grupo focal 03 - 12 convidados, 09 participantes e 03 abstenções.

Foi utilizada a técnica de análise temática para tratamento dos dados. Essa técnica propõe a descoberta de núcleos de sentido, isto é, o surgimento dos pontos centrais de significação que, inseridos no discurso, expressariam, através de sua aparição e freqüência, os valores de referência e os modelos de comportamento numa perspectiva qualitativa (Minayo, 2004). É realizada em três fases:

- Pré-análise - Fase em que o pesquisador, com o material já coletado, realiza uma leitura flutuante do mesmo;

- Exploração do material - É uma fase de codificação, em que se classificam e se agregam os dados em categorias teóricas ou empíricas que organizarão os temas;

Tratamento dos resultados obtidos e interpretação - Nessa fase, são interpretados os dados, segundo a dimensão teórica adotada.

O que pensam os alunos de graduação em Psicologia sobre...

\section{A realidade da população}

O contato dos alunos com a realidade da clientela que busca o plantão psicológico 
permitiu-lhes a constatação das expectativas dessa população. De maneira geral, os relatos dos alunos mostram que há um desconhecimento, por parte da clientela, do trabalho do psicólogo, trabalho visto de maneira preconceituosa, como uma atividade que lida com a loucura. O profissional (psicólogo) e a ciência (Psicologia) são aqueles a quem se recorre quando falharam todas as instâncias e alternativas. A Psicologia aparece, no imaginário popular, em grande parte, como uma possibilidade que, antes de ser associada a um benefício, é, pela maior parte dos pacientes, considerada um legitimador de sua inadaptabilidade ao mundo. Maluf (1996); Maluf (2003) e Bock (2003), refletindo sobre essa questão, consideram que a Psicologia, em nosso país, instituiu-se e legalizou-se enquanto profissão, com finalidades de normatização e controle. A Psicologia da norma era indicada aos desviantes; posteriormente, em decorrência do processo de desospitalização, insere-se nas unidades de saúde através dos ambulatórios de saúde mental e hospitais psiquiátricos, numa ação mais curativa e profundamente vinculada à psiquiatria, pela falta de uma identidade e definição do papel social do psicólogo, conforme argumentam Spink, (1985), Ocampo e Arzeno (1997), Pessotti (1988), Spink (1992), Cunha (1993) e Spink (2003).

Analisando as respostas dos grupos focais, pudemos observar que as expectativas (percebidas pelos alunos) da população assistida referem-se, em sua grande maioria, à tentativa de solução de problemas imediatos. Essas expectativas contemplavam a manifestação do desejo de serem ajudados de maneira muito peculiar, atendendo à particularidade de cada um, porém, em todas as respostas, havia um pedido de solução para algo específico que os acometia.

Assim, pode-se observar, na fala dos entrevistados, uma certa frustração e dissonância entre o que eles entendiam como “projeto psicoterápico” (Costa, 1989; Bezerra Junior, 1996) e aquilo que a população buscava e esperava enquanto tratamento.

“... ele quer ser atendido, ele quer ser ouvido naquele momento. Se a dor dele é aquele dia que está ali no plantão, não importa se vai vir pra outra sessão, ele quer ser acolhido, quer ser escutado... naquele momento em que a gente estava ouvindo o paciente, pra ele já era importante e saía aliviado. De repente, você ligava pra ele vir para a próxima sessão: 'não... não me interessa mais’...” (Petúnia, GF 2).

O discurso dos clientes (sempre pela ótica dos entrevistados, isto é, dos ex-alunos plantonistas) revelou um desconhecimento sobre como se desenvolve o trabalho do psicólogo. Os pacientes mostraram esperar um socorro, uma ajuda, um alívio imediato para minimizar os danos a que estavam submetidos. Algumas falas revelam o que os alunos perceberam do discurso da clientela, no primeiro dia de plantão, o que está de acordo com Mahfoud (1987), quando se refere à busca pelo plantão:

“... o primeiro momento deles era assim como se eles tivessem buscando, é... uma solução imediata daquele sofrimento. O primeiro momento era alívio do sofrimento, mas era como se fosse uma mágica pra eles, era uma solução rápida que eles queriam, que eles viriam e sairiam curados daquele sofrimento" (Gardênia, GF 2).

“... é o fato de ser o plantão mesmo. É o momento que o paciente está vivendo, é a crise. Então quando ele vem com essa expectativa, eu acho que é pra alguém que acolha, alguém que escute, alguém que esteja ali com ele no momento mais forte, que é o momento da dor..." (Jasmim, GF 2).

As pessoas que procuravam o plantão manifestavam o desejo de encontrar alguém sobre-humano para prestar ajuda, atribuíam uma imagem onipotente ao psicólogo ou 
esperavam a solução de problemas através de uma ação diretiva desse profissional:

“... [alguém] que já teria procurado outros recursos, mil situações e chegou na sua mão... '...eu tô vendo você como alguma coisa que vai me dar um caminho, pra eu poder daqui tocar a minha vida, porque eu cheguei num ponto que eu não tenho mais o que fazer, eu não sei mais como lidar e eu espero de você seja essa luz, um caminho pra eu tocar a minha vida’...” (Gérbera, GF 2).

“... às vezes, ele não sabe o que ele vai encontrar, mas ele fantasia muito também em relação à figura do psicólogo... em relação ao que encontraria: a mágica para os seus problemas, e tudo mais. E aí, de repente, ele se depara com uma coisa nova pra ele e que mostra outros caminhos...” (Gérbera, GF 2).

A busca pelo plantão psicológico, como última possibilidade de ajuda, poderia representar a tentativa de superar o próprio preconceito com relação à doença mental, pois, em quase todos os relatos, está presente a expectativa de acolhimento, atenção e aceitação, veiculada por uma atitude não crítica, confirmando o que propõem Mahfoud (1987), Cury e Di Nucci (1998) e Cury (1999) quando refletem sobre a prática do plantão psicológico, não enquanto resolubilidade do problema, mas como possibilidade alternativa para a transposição de obstáculos decorrentes da própria vida de cada paciente.

“... tem que passar por cima de muitas coisas pra admitir que você precisa de um psicólogo... vai em posto, em hospital, mas pra você passar por cima de algo [uma idéia] que você já tem, de que psicólogo cuida de louco, 'o quê que vão pensar, meu marido, meu pai' ... vê que todas as especialidades que você procurou não atenderam, não ajudaram, aí você tem que engolir e falar: 'eu preciso de um psicólogo'..." (Dália, GF 2).
Quanto às necessidades observadas pelos alunos no contato com os pacientes em plantão, não são da ordem de uma assistência psicológica de longo prazo. As necessidades citadas pelos entrevistados evidenciam necessidades individuais de reconhecimento, de respeito e de aceitação. Algumas das falas abaixo especificam necessidades de acolhimento e escuta:

"Eu acho que tem a questão de ser visto como alguém que está ali, que é importante, que quer ser ouvido, que quer ser enxergado... 'eu tenho uma família, mas ninguém consegue entender... ah, ninguém consegue perceber que eu estou precisando de um momento pra falar'..." (Magnólia, GF 3).

Alguns dos pacientes mostravam necessidades de receitas prontas; esse pedido está implicado no “projeto psicoterápico” dessa população, cuja dimensão de passado e futuro implícitos no reordenamento simbólico é inviabilizada pelas características de seu aprendizado cultural, em função do imediatismo que permeia a vida desses pacientes, como nos alertam Costa (1989) e Bezerra Júnior (1996). Nos relatos seguintes, pode-se observar novamente o desconhecimento sobre como trabalha o psicólogo, e, em conseqüência, a associação do seu trabalho ao modelo médico.

“... além da atenção que eles buscavam, eles vinham procurando alguém que fosse dar uma solução pros problemas, queriam ouvir da psicóloga 'não, você vai fazer isso, isso e isso', então não tem como... receita pronta..." (Prímula, GF 1).

Outros demonstravam a demanda por uma vida normal, sem grandes ambições quanto a um projeto psicoterápico. Bezerra Júnior (1996) e Costa (1989) pontuam que a necessidade de situar-se no parâmetro determinado socialmente pode levar o indivíduo a um estado de sofrimento:
"... além da atenção que eles buscavam, eles vinham procurando alguém que fosse dar uma solução pros problemas, queriam ouvir da psicóloga 'não, você vai fazer isso, isso e isso', então não tem como... receita pronta..."

Prímula, GF 1 
"... e tinha os que descobriam alguma coisa ali... tão importante pra eles que eles queriam vir mais vezes... ele falou que era como se ele estivesse em uma caixa, bem grande, que vai abrindo uma caixa, abrindo outra, abrindo outra e ele tava

bem na última caixa, no cantinho. E... de uma passagem para a outra, ele eliminava um monte de fantasmas"

Hortência, GF 3
“Ah, 'de aceitação na família, de ter uma vida normal',... alguns pacientes colocavam, mesmo, que não conseguiam ter vida normal devido a algum problema, devido ao que trazia na clínica. Então, às vezes, eles se achavam... fora do padrão esperado e que vinha buscar isso da gente...” (Margarida, GF 3).

Entretanto, outros relatos descrevem a descoberta da possibilidade de autoconhecimento pela melhora da percepção de si, do seu problema e dificuldade, o que propicia uma condição de aprofundamento, pela continuidade do processo terapêutico. Bellak e Small (1980), Knobel (1986), Braier (2000) e Lowenkron (2000) consideram essa uma das possibilidades dos atendimentos breves, quando o paciente vem a obter, através de um período limitado de tempo em terapia, a oportunidade de abrir-se a um questionamento maior e continuar seu processo de ressignificação.

“... e tinha os que descobriam alguma coisa ali... tão importante pra eles que eles queriam vir mais vezes... ele falou que era como se ele estivesse em uma caixa, bem grande, que vai abrindo uma caixa, abrindo outra, abrindo outra e ele tava bem na última caixa, no cantinho. E... de uma passagem para a outra, ele eliminava um monte de fantasmas” (Hortência, GF 3).

\section{A experiência no plantão psicológico}

O ambiente de aprendizagem do plantão psicológico trouxe, ao aluno, a vivência de uma realidade pouco conhecida e, por vezes, temida, mas, ao mesmo tempo, sentida como um desafio constante, muito semelhante ao referido por Mahfoud (1987). Nossos entrevistados descrevem suas experiências demonstrando ansiedade, medos, satisfação e crítica.

Dentre as dificuldades apontadas, estão a ansiedade, o medo e a insegurança. Tais aspectos "dificultadores" ocorreram no percurso não controlado que o plantão determina, ou seja, o momento do plantão parece constituir-se sempre em um momento inicial, dado que só ocorre nessa vivência, uma vez que, em outras disciplinas, o estágio será realizado com o mesmo paciente durante mais de um semestre, e, além disso, com um paciente de quem já se tem alguma informação em prontuário.

Para os entrevistados, a ansiedade ocorreu pela expectativa do elemento surpresa, pelo desconhecimento da queixa e pelo receio da crítica caso não conseguissem circunscrever essa queixa em uma linguagem tecnicamente correta no momento da exposição do caso ao supervisor. Esses dados coincidem com os achados de Yehia (1996b); Herzberg (1999); Telles e Wanderley (2000), Nogueira-Martins (1998) e Nogueira-Martins (2001).

“... a vontade de querer acertar... acho que a gente acaba ficando tão tensa, pensando 'ai... como será esse paciente que eu vou atender daqui a alguns minutos' ...você ficava com aquele medo de errar, de você não poder ajudálo, na medida que ele tava precisando naquele momento. Então, pra mim, uma dificuldade grande foi a vontade de querer acertar e muito medo de errar..." (Brinco de Princesa, GF 3).

O medo e a insegurança incidiram no contato inicial com o paciente, associados à fantasia sobre “quem seria esse paciente", pelo receio que o aluno tinha de se perder, não sabendo como e quando falar, pelo temor de se confundir e não discriminar aquilo que seria seu com o que seria do paciente, pelo medo de se emocionar, de errar e de ser avaliado. Herzberg (1999), Aguirre et al. (2000), Telles e Wanderley (2000), ao discorrerem sobre o processo de construção da identidade do psicólogo para o desempenho de seu papel, alertam para o fato de que esse processo exigirá do aluno mais do que a compreensão teórica e técnica do fenômeno psicológico, e irá transitar na complexidade de sua subjetividade. 
“... o meu medo era de chegar lá e não saber o que me esperava e não dar conta. 'E aí, o quê que é que eu vou fazer aqui? Não posso sair daqui e buscar o supervisor... eu tenho que dar conta aqui dentro...' Na primeira visita do paciente, me dava essa ansiedade” (Gardênia, GF 2).

O aluno, nesse momento, vivencia sentimentos de grande exigência e confusão com relação a seu papel, ao mesmo tempo em que parece se desapropriar de seus saberes, cabendo ao supervisor um papel duplo, o de facilitar o aprendizado do aluno e o de preservar o atendimento adequado ao paciente, como propõe Yehia (1996a).

"Eu acho que a grande dificuldade é a própria ansiedade nossa, em saber o que a gente vai fazer, essa questão da surpresa, o que vai chegar ali na minha frente... e o que vou fazer com aquilo...” (Flor de Maio, GF 3).

Os próprios sentimentos que emergem no atendimento, muitas vezes interferindo no contato inicial com o paciente, foram apontados pelos alunos como algo complexo e difícil de ser administrado, como podemos perceber nesses relatos, que coincidem com os dados encontrados por Ancona-Lopes (1996), Herzberg (1999), Aguirre et al. (2000), Telles e Wanderley (2000) e Nogueira-Martins (2001).

"Eu acho que o mais importante disso tudo é depois a gente conseguir parar e compreender, compreender porque você sente raiva... em um atendimento com uma moça que tinha a mesma idade que eu e que sofreu violência sexual, eu pensava, 'aí, e se fosse comigo?' ... O mais difícil não foi atendê-la, mas perceber o que aquilo tinha causado em mim... então é um ponto muito difícil pra todas nós...” (Tulipa, GF 1).

O discurso dos entrevistados mostrou que houve dificuldade do aluno em lidar com questões restritivas da clínica-escola, o que também é citado por Ancona-Lopes (1981),
Ancona-Lopes (1986), Schmidt (1992), Ancona-Lopes (1995) e Castro (1998), no que diz respeito às clínicas-escola que, enquanto instituições, priorizam a formação, mas acabam suprindo importante parcela de contribuição no trabalho com a saúde mental. Essa dificuldade tem uma função importante na formação do aluno; ao mesmo tempo em que desilude o futuro psicólogo, funcionando como um elemento desalentador ao imprimir, no aluno, os limites institucionais, também deflagra uma visão crítica do Estado, pelo descaso com que são tratadas as questões da saúde mental. Essa perda de entusiasmo inicial produz, no aluno, a reflexão sobre sua própria profissão, sua formação, o compromisso social inserido em sua profissão.

“... eu acho que uma parte de dificuldade... de ter uma demanda muito grande no plantão e a gente encaminha e fica angustiada que a pessoa está na fila de espera... Como você acolhe no plantão, faz os três atendimentos, quatro, e encaminha para um grupo ou para individual, você encaminha... aí ela não tem condições de ir pra um outro lugar [rede pública ou privada]... Quer dizer, foi um trabalho que eu acolhi e que eu sei que só daqui a três anos ela vai ser atendida...” (Azálea, GF 2).

Os aspectos facilitadores da atividade foram: estrutura curricular do curso, supervisão enquanto estratégia de aprendizagem e a presença dos supervisores.

O preparo teórico e a estrutura curricular do curso, com disciplinas de pré-requisito e com enfoque na comunidade, foram considerados facilitadores para o processo de aprendizagem.

“... a formação acadêmica possibilitou a gente estar muito próximo da comunidade... próximo de quem realmente necessita, de quem precisa, acho que essa é uma grande característica de um psicólogo... atuando na comunidade para melhoria da comunidade. E isso é o próprio curso, que é enfocado na comunidade... então,
"... eu acho que uma parte de dificuldade... de ter uma demanda muito grande no plantão e a gente encaminha e fica angustiada que a pessoa está na fila de espera... Como você acolhe no plantão, faz os três atendimentos,

quatro, e encaminha para um grupo ou para individual, você encaminha... aí ela não tem condições de ir pra um outro lugar [rede pública ou privada]... Quer dizer, foi um trabalho que eu acolhi e que eu sei que só daqui a três anos ela vai ser atendida..."

Azálea, GF 2 
o meu projeto futuro tem relação com a comunidade também” (Petúnia, GF 3).

No tocante à supervisão, as falas revelaramna um espaço de "reasseguramento", troca e de redução da ansiedade, ampliando o conforto e a disponibilidade para vivenciar o papel bem como, aumentando a visibilidade da Psicologia enquanto prática e atuação. A relação de confiança que vai se instituindo na supervisão através da atitude de acolhimento do supervisor colabora para o desenvolvimento do papel de plantonista, minimizando os aspectos negativos dessa vivência (Buys, 1987; Herzberg, 1996; Nogueira-Martins, 1998; Telles e Wanderley, 2000; Nogueira-Martins, 2001).

O trabalho no plantão psicológico traz consigo um momento bastante ambíguo, pois é simultaneamente ansiógeno e desejado pelo estudante. Nesse sentido, a presença do supervisor será fundamental nessa passagem do aluno ao papel de psicólogo plantonista, como encontramos em Herzberg (1999), Aguirre et al. (2000), que consideram o papel do supervisor, em qualquer atendimento, o daquele que, permitindo a compreensão do aluno sobre o significado do enquadre de sua tarefa, possibilitar-lhe-á essa vivência, desenvolvendo sua identidade profissional, tão importante na assunção de seu papel como profissional de saúde.

" $a$ ansiedade era grande; às vezes eu me sentia mais amparada do que agora... Você vê: eu ainda não comecei a atender... a gente tinha as supervisões, então, é claro que dava aquela angústia e aquela ansiedade, de 'ai meu Deus do céu, vou atender um paciente suicida, será que eu vou conseguir? e agora?' Mas tinha a supervisão, sei lá, dava um apoio...” (Lírio, GF 1).

A certeza da presença do supervisor, enquanto mediador e, de certa maneira, fornecedor de um modelo (não pronto, já que nem mesmo o supervisor conhece a demanda que irá aparecer no plantão), contribui para a construção de um primeiro debate sobre a solução mais adequada ao caso, aproxima o aluno de um raciocínio clínico e viabiliza a reflexão ética da prática psicológica, pois compreende o erro e administra o acerto. Disso, depreendemos ser necessária certa maturidade para o funcionamento desse trabalho e para o tipo de supervisão desenvolvida. Os relatos dos alunos falam de uma relação onde a "modelagem de interiores”, descrita por Baptista (1987), pôde dar lugar à autonomia, não se tornando um obstáculo ao desenvolvimento do trabalho do futuro profissional.

“... Os supervisores tratam a gente como profissional mesmo, então eles dão toque, eles avisam, estão muito próximos. Eu acho que essa igualdade de passar o conhecimento... conseguir com que a gente tenha essa liberdade, que se sinta acolhido... construir juntos o conhecimento... faz com que a gente aprenda muito mais e fique um pouco mais à vontade... a gente está muito próximo do supervisor, eles estão muito do seu lado” (Petúnia, GF 3).

Os alunos se referiram à maneira pela qual os supervisores passaram a idéia de plantão, conferindo-lhe credibilidade, ao reconhecer que o exercício da prática profissional é determinado pelas tramas da ideologia, concepção de mundo e interesses pessoais de quem atua (Mitjáns-Martinez, 2003). É o sujeito "psicólogo" que se apropria dos conhecimentos da Psicologia, destinando-os a uma utilização comprometida socialmente.

Cabe aqui a ressalva de que todos os supervisores que se incluíam nesse recorte eram professores que, além de uma formação acadêmica coerente, contavam com uma experiência profissional bastante ampla, além de uma grande disponibilidade para a realização desse trabalho, que exigia, além do conhecimento, certa flexibilidade para administrar tanto as adversidades institucionais 
como as decorrências de demandas inusitadas, o que pressupõe uma disposição à revisão do instituído e à minimização do dogmatismo (Bezerra Júnior, 1992; Schmidt, 1992; Andrade, 1996; Mello, 1996).

"Acho que o que facilitou também a nossa atuação no plantão foi a forma até como os supervisores passaram... eles passaram com uma paixão, com uma responsabilidade... isso trouxe uma disponibilidade já dentro de nós, porque eu acho que poderia ter sido também um desastre o plantão, se, de repente, passassem de uma forma que não fosse segura, que não fosse legal, que não fosse oferecer suporte pra ajudar... Acho que isso já trouxe uma disponibilidade dentro... você fala 'eu quero, eu vou abraçar isso e vou até o fim" " (Hortência, GF 3).

\section{O papel do psicólogo}

As vivências no estágio proporcionaram aos alunos maior contato com a realidade dos clientes assim como uma ampliação na ótica do “fazer psicologia”; nessa inserção, o modelo pronto sofreu ajustes para atender as demandas; parece que se desmantelou a idéia de uma psicologia pronta que seria aplicada em qualquer circunstância, com qualquer população (Bezerra Junior, 1992; Silva, 1992; Mello, 1996; Spink, 2003). A inserção no plantão psicológico mostrou ao aluno a necessidade de certa flexibilidade e ajuste às necessidades e peculiaridades da população que é assistida e despertou a necessidade de intervenções concretas de "vigilância da saúde”, que resultam da combinação de promoção à saúde, prevenção da doença e ação curativa, conforme descreve Mendes (1996).

“... mesmo nos casos de desespero, o acolhimento que a gente dá, eu acho que até é meio como um aspecto preventivo. Porque a pessoa chega no desespero... 'não agüento mais’ e de repente... poder desabafar... 'eu estou sem emprego, não passo na entrevista'... e em três, quatro atendimentos, essa pessoa conseguiu emprego, parece que levantou..." (Lírio, GF 1).

É colocada, assim, a ampliação de uma visão mais aberta para o mundo, ao atender, através de propostas pertinentes, as necessidades das comunidades, o que altera o alcance do exercício da Psicologia (Lo Biancho et al., 1994).

“... abriu um leque, abriu um espaço pra gente conhecer como funciona lá fora, como que é a realidade, quebrando essa visão da clínica, fechada, bonitinha, e... então é um contato maior com as divergências, de não ter ali tudo preparado, não ter um ambiente correto, adaptado pra estar atendendo...” (Girassol, GF 3).

A experiência do plantão mostrou-se uma prática disruptora e transformadora que, estendida a outras situações, permitiu aos alunos a possibilidade de lidar com a “processualidade emergente” (Andrade, 1996; Vilela, 1996), isto é, propiciou ao aluno a vivência da função de psicólogo pelo acolhimento do emergente, do diferente, do excluído.

“... eu entrei no Distrito Policial com a experiência de fazer o estágio e prestar conta lá das 35 horas de Institucional ${ }^{2}$ e acabou sendo puro plantão psicológico, também, porque as demandas eram as mais diversas, desde o estupro, a mulher vitimizada, da violência psíquica, da violência física, todo o tipo de violência que você pudesse imaginar passava por nós... o que nos instrumentalizou a dar conta foi o plantão psicológico...” (Camélia, GF 2).

\section{A Psicologia e a saúde mental}

A realidade da saúde mental se impõe no contato direto com aquilo que é trazido pelo paciente, através de seu discurso, e mostra a pouca importância dada à saúde mental das
2 Estágio da disciplina Psicologia Institucional e Comunitária I e II. 
populações, exigindo uma nova configuração para a prática da psicologia, numa tomada de posição política (Macedo, 1986; Costa, 1989; Bock, 1991; Spink, 1992; Bock, 1996; Spink, 2003).

"À medida em que você trabalha com suas habilidades, com essa criticidade dentro da Psicologia, a sua contribuição com certeza não vai ser fragmentada. Ela vai sempre oferecer uma qualidade de vida muito maior em qualquer que seja a situação em que você esteja, em qualquer instituição que você esteja...” (Camélia, GF 2).

As respostas dos entrevistados mostram uma

"... quando você faz um

encaminhamento... e, muitas vezes, o paciente até tenta e não consegue por causa da nossa realidade... é muito frustrante, porque a gente fica de braços abertos aqui,

querendo ajudar, e quando a gente vê que não depende mais da gente... aí fica aquele ponto de interrogação..."

Gerânio, GF 1

3 Os casos considerados graves no atendimento em plantão foram os casos de pacientes esquizofrênicos, psicóticos, borderlines, com riscos suicidas $e$ condição socioeconômica bastante restrita, para quem o trabalho desenvolvido no plantão psicológico da instituição $e ́$ insuficiente, não lhes restando alternativas de tratamento a não ser nos serviços públicos, já que os privados não lhes são acessíveis. necessidade de desmitificação da função e papel do psicólogo para o trabalho com a grande massa. A idéia atribuída à profissão está muito associada ao "médico dos loucos", portanto, ir ao psicólogo é assumir também sua provável insanidade. Os entrevistados que, lidando com a população do plantão, foram comparados a esse profissional da loucura, nessa vivência de alteridade, explicitam a necessidade de se desconstruir essas representações, que se perpetuam por gerações e gerações (Spink, 2003). Os entrevistados falam da necessidade de esclarecimento sobre o trabalho do psicólogo, que possibilitaria uma compreensão mais ampla e romperia o preconceito que cerca a doença mental.

“... existe um mito muito grande aí, quando se fala em saúde mental, porque as pessoas vinculam o psicólogo à loucura... quando você faz um curso de Psicologia... traz isso muito pra perto de você... você passa a fazer parte disso, e é difícil lidar com isso também... mas, de uma outra forma, possibilita que você mude talvez a idéia daquela pessoa... a questão da saúde mental e a Psicologia... é questão de tentar desmitificar um pouco...” (Magnólia, GF 3).

As principais dificuldades comentadas pelos alunos, ao se referirem às políticas de saúde pública, foram relacionadas à impotência vivida no atendimento de casos graves ${ }^{3}$, que não podem ser tratados de maneira efetiva nas condições de serviços de uma clínica-escola. O trabalho no plantão também evidenciou a importância do ensino para uma atuação nos diversos níveis da saúde pública (atenção primária, secundária e terciária), como propõem Bellak e Small (1980).

Observa-se que, dentro das possibilidades, a clínica-escola realiza um trabalho bastante eficaz, contudo, necessita de muita flexibilidade para lidar com um dos grandes obstáculos apontado pelos entrevistados, que diz respeito à falta de um médico psiquiatra para o acompanhamento dos casos em que são necessárias ações medicamentosas imediatas e/ou contínuas. Nessa situação, o aluno vivencia, junto ao seu supervisor, sentimentos de impotência e desânimo, já que o acesso do paciente à rede pública vai depender de condições reconhecidamente precárias.

“... quando você faz um encaminhamento... $e$, muitas vezes, o paciente até tenta e não consegue por causa da nossa realidade... é muito frustrante, porque a gente fica de braços abertos aqui, querendo ajudar, e quando a gente vê que não depende mais da gente... aí fica aquele ponto de interrogação...” (Gerânio, GF 1).

O que cabe às clínicas-escola, nessa perspectiva? Cumprir o papel do Estado? Pensamos que não; sua meta deveria ser investir na pesquisa, trazer à discussão interna os grandes temas da sociedade contemporânea, formando não psicólogos alienados, mas sujeitos pensantes. Além disso, parece-nos que o papel do agente formador seria não só prover o aluno de uma tomada de posição ético-política mas também permitir ao próprio cliente sua conscientização, já que, alienado e temeroso por pertencer à categoria dos excluídos, omite-se na cobrança de seus 
direitos mínimos, cala-se para não revelar e/ ou legitimar sua condição de "doente mental”, e, com isso, perde a possibilidade de se tornar cidadão.

\section{Considerações finais}

Ao iniciarmos este trabalho, perguntávamos o quanto a inserção do aluno em uma atividade assistencial na graduação favoreceria a instalação de uma consciência crítica de nossa realidade social e uma reflexão sobre a prática da Psicologia. Essa questão apresentou-se amplamente discutida e refletida na fala dos entrevistados, que mostrou que a atividade de plantão psicológico foi fomentadora de desilusões e rupturas, permitindo, a cada um, uma nova construção na maneira de olhar para antigas questões, explicitando-se a necessidade de questionar e avaliar as práticas cotidianas.

O trabalho em plantão psicológico revelou-se uma forma de prática que rompe o conforto secular de saberes e fazeres garantidos e assegurados pelo universalismo do pensamento ocidental, trazendo, ao bojo das discussões, a necessidade de se questionar as práticas exercidas junto à população, o modelo de Psicologia instituído e as necessidades políticosociais subjacentes à manutenção dessas práticas.

As necessidades e expectativas contidas no "pedido de ajuda psicológica" dos clientes foram percebidas em uma amplitude muito maior do que pode significar uma oferta psicoterápica nos moldes tradicionais. O contato vivido pelos entrevistados, na condição ainda de alunos, re-conectou o aprendido e o vivido e determinou uma certeza: a de que o exercício da Psicologia não é algo acabado, ao contrário, é um devir constante.

As dificuldades na vivência do papel de psicólogo plantonista estiveram ancoradas nos aspectos pessoais derivados da ansiedade, medo e insegurança da nova vivência; esses aspectos, habitualmente, desencadeiam uma autocobrança e auto-exigência que, se não bem trabalhadas e discutidas, imobilizam a ação daqueles que as experimentam.

Os aspectos facilitadores da inserção no plantão foram o contraponto; gradativamente, deram lugar à construção de uma imagem profissional, lapidada pelo preparo teórico, pela estrutura curricular do curso e pelo reconhecimento da função preponderante da supervisão. Esse espaço de "reasseguramento" criou condições favoráveis à reedição do já aprendido, agregando, pela singularidade, as demais vivências e saberes, em um processo de experiência vivida, de subjetivação do papel de psicólogo.

As mudanças da ótica do aluno repercutem na sua maneira de se colocar criticamente, em se incluir como sujeito ativo e participativo no processo de mudança de amadurecimento da ciência psicológica.

A tríade saúde mental $\mathrm{X}$ Psicologia $\mathrm{X}$ saúde pública sugere a necessidade de ampliar a esfera do trabalho psicológico, não como uma prática coercitiva e de controle, para a qual só se retorna quando todas as demais práticas já falharam. É função do psicólogo humanizar sua prática, desfazer sua imagem estereotipada, esclarecer e divulgar seu trabalho e, com isso, favorecer o rompimento do preconceito. Da mesma forma, é sua função desmitificar a doença mental e ampliar a visão da saúde mental. Para isso, o psicólogo há que buscar sanar suas deficiências teóricas e técnicas na atuação e prática diária do profissional, repensando-as.

É necessário avivar a discussão sobre o papel da universidade na gestação dos saberes e práticas. Especificamente, as clínicas-escola, em sua função social, precisam continuar desenvolvendo ampla reflexão sobre essas práticas, tornando o tripé da formação pesquisa, ensino e serviço - contextualizado na realidade e orientado à construção de um lugar de reflexão e investigação de práticas mais humanizadas. 


\section{Rosélia Bezerra Paparelli}

Professora pesquisadora - Faculdade de Psicologia da Universidade Camilo Castelo Branco-

UNICASTELO; coordenadora clínica do Centro de Formação de Psicólogos da Faculdade de Psicologia da Universidade Camilo Castelo Branco-UNICASTELO (2002 a 2005); professora da Universidade São Francisco/USF; psicóloga, Mestre em Ciências pelo Programa de Pós-Graduação em Ciências da Secretaria de Saúde do Estado de São Paulo.

E-mail: roseliabp@gmail.com

\section{Maria Cezira Fantini Nogueira-Martins}

Pesquisadora científica do Instituto de Saúde da Secretaria de Estado da Saúde de São Paulo. Psicóloga, Doutora em Distúrbios da Comunicações Humana pela Universidade Federal de São Paulo, Pós-

Doutorado em Metodologia de Pesquisa Clínico-Qualitativa na Universidade Estadual de Campinas.

Docente do Programa de Pós-Graduação em Ciências da Secretaria de Estado de Saúde de São Paulo. E-mail: mcezira@yahoo.com.br 
AGUIRRE,A.M.B.,HERZBERG,E.,PINTO,E.B., BECKER,E.,CARMO, H. M. S., SANTIAGO, M. D. E. A Formação da Atitude Clínica no Estagiário de Psicologia. Psicologia USP, Sã̃o Paulo, 11, 1, pp. 49-62, 2000

ANCONA-LOPES, M. Avaliação de Serviços de Psicologia Clínica (dissertação). Pontifícia Universidade Católica de São Paulo. São Paulo, 1981.

ANCONA-LOPES, M. Características da Clientela de Clínicas-escola de Psicologia em São Paulo. In: Macedo, R. M. Psicologia e Instituição - Novas Formas de Atendimento. $2^{\mathrm{a}}$ ed. São Paulo: Cortez; 1986, pp. $24-46$.

ANCONA-LOPES, M. (org.) Psicodiagnóstico - Processo de Intervenção. São Paulo: Cortez, 1995.

ANDRADE, N. A. A Angústia Frente ao Caos - um Estudo Genealógico da Formação do Psicólogo Clínico (tese). Pontifícia Universidade Católica de São Paulo. São Paulo, 1996.

BAPTISTA, L. A. S. Algumas Histórias sobre a Fábrica de Interiores (tese). Universidade de São Paulo. São Paulo, 1987.

BELLAK, L., SMALL, L. Psicoterapia de Emergência e Psicoterapia Breve. Porto Alegre: Artes Médicas, 1980.

BEZERRA JÚNIOR, B. Prefácio. In: Campos, F. C.B. (org.). Psicologia e Saúde - Repensando Práticas. São Paulo: Hucitec, 1992, pp. 8 - 9.

BEZERRA JÚNIOR, B. Considerações sobre Terapêuticas Ambulatoriais em Saúde Mental. In: Tundis, A. S., Costa, N.R. (orgs.) Cidadania e Loucura: Políticas de Saúde Mental no Brasil. São Paulo: Editora Vozes, 1996, pp. 133 - 169.

BOCK, A. M. M. Pensando a Profissão do Psicólogo, ou: Eu, Caçador de Mim (dissertação). Pontifícia Universidade Católica de São Paulo. São Paulo, 1991.

Questões sobre a Formação do Psicólogo. In: Anais do IV Encontro Estadual de Clínicas - escola. Universidade Paulista - UNIP, São Paulo, pp. 19-19,1996.

O Estatuto Científico das Práticas Clínicas In: Anais do VI Encontro Estadual de Clínicas - escola. Universidade São Francisco, São Paulo, pp. 16-20,1998.

Psicologia e sua Ideologia: 40 Anos de Compromisso com as Elites. In: Psicologia e Compromisso Social Bock, A. M. M.(org). São Paulo: Cortez Editora, 2003, pp. 15- 28.

BRAIER, E.A. Psicoterapia Breve de Orientação Psicanalítica. São Paulo: Martins Fontes, 2000

BUYS, R. C. Supervisão de Psicoterapia na Abordagem Humanista Centrada na Pessoa. São Paulo: Summus, 1987.

CASTRO, E. O. A Formação Clínica do Psicólogo. In: Anais do VI Encontro Estadual de Clínicas - Escola. Universidade São Francisco, São Paulo, pp. 129 - 141, 1998.

COSTA, J. F. Psicanálise e Contexto Cultural : Imaginário Psicanalítico, Grupos e Psicoterapias. Rio de Janeiro: Editora Campus, 1989.

CUNHA, J. A. Psicodiagnóstico. Porto Alegre: Artes Médicas, 1993.

CURY, V.E., DI NUCCI, S. H. P. Plantão Psicológico como Intervenção na Clínica-escola da PUC-Campinas. In: Anais do VI Encontro Estadual de Clínicas - escola. Universidade São Francisco, São Paulo, pp.71-74, 1998.

CURY, V. E. Psicólogos no Plantão. In: Mahfoud, M. (org.). Plantão Psicológico: Novos Horizontes. São Paulo: Companhia Limitada, 1999.

HERZBERG, E. Efeitos Psicoterapêuticos do Processo Psicodiagnóstico: Vivências do Psicólogo em Formação. Anais do Congresso Nacional de Avaliação Psicológica, Porto Alegre, pp.69$75,1999,8$.

KNOBEL. M. Temas Básicos de Psicologia: Psicoterapia Breve. São Paulo: EPU, 1986.

LO BIANCO, A. C., BASTOS, A.V.B., NUNES, M.L.T., SILVA, R. C. Concepções e Atividades Emergentes na Psicologia Clínica: Implicações para a Formação. In: Conselho Federal de Psicologia. Psicólogo Brasileiro - Práticas Emergentes e Desafios para a Formação. São Paulo: Casa do Psicólogo, 1994, pp. 7 - 79.

LOWENKRON, T. S. É Possível Psicanálise Breve? Revista Latinoamericana de Psicopatologia Fundamental, São Paulo: 3 : 4, pp. 59 - 79, 2000.
MACEDO, R. M. Psicologia, Instituição e Comunidade. In: Macedo, R. M. (org.), Psicologia e Instituição: Novas Formas de Atendimento. $2^{\text {a }}$ ed. São Paulo: Cortez Editora, 1986, pp. 9 - 23.

MAHFOUD, M. A Vivência de um Desafio: Plantão Psicológico. In: Rosemberg, R. (org). Aconselhamento Psicológico Centrado na Pessoa: São Paulo: EPU, 1987.

MALUF, M. R. A Formação Profissional do Psicólogo Brasileiro. Interações, São Paulo, 1-1, pp. 31 - 45, 1996.

MALUF,M.R.,CRUCES,A VV.,SALAZAR, R, LINARD, V.Autorização e reconhecimento de cursos de graduação em Psicologia no Brasil. 2003: Site - www.mrmaluf.com.br/autorizacao.htm acessado em 06.04.2004 - 10h:35m.

MENDES, E. Uma Agenda para a Saúde. São Paulo: Hucitec, 1996

MELLO, S. L. A Formação do Psicólogo. In: Cadernos de Psicologia, Belo Horizonte, 4, 5, pp. 11 - 17, 1996.

MINAYO, M. C. S. O Desafio do Conhecimento. $8^{\mathrm{a}}$ ed. São Paulo: Hucitec, 2004.

MITJÁNS-MARTINEZ, A. Psicologia e Compromisso Social: Desafios para a Formação do Psicólogo. In: Bock, A. M. B (org.), Psicologia e o Compromisso Social. São Paulo: Cortez Editora, 2003.

MORATO, H. T. P. Serviço de Aconselhamento Psicológico do IPUSP: Aprendizagem Significativa em Ação. In: Aconselhamento Psicológico Centrado na Pessoa - Novos Desafios. São Paulo: Casa do Psicólogo, 1999.

NOGUEIRA-MARTINS, M. C. F. A Transição Estudante Fonoaudiólogo: Estudo Qualitativo sobre a Vivência dos Primeiros Atendimentos (tese). Universidade Federal de São Paulo/ Escola Paulista de Medicina. São Paulo, 1998.

Humanização das Relações Assistenciais: a Formação do Profissional de Saúde. São Paulo: Casa do Psicólogo, 2001.

NOGUEIRA-MARTINS, M. C. F., BÓGUS, C. M. Considerações sobre a Metodologia Qualitativa como Recurso para o Estudo das Ações de Humanização em Saúde. Saúde e Sociedade, São Paulo, v.13, n. 3 , pp. 44 - 57, 2004.

OCAMPO, M. L. S., ARZENO, M. E. G. O Processo Psicodiagnóstico. In: O Processo Psicodiagnóstico e as Técnicas Projetivas. São Paulo: Martins Fontes, 1987.

PESSOTTI, I. Notas para uma História da Psicologia Brasileira. In: Quem É o Psicólogo Brasileiro? São Paulo: Edicon, 1988, pp. 17 - 31.

SCHMIDT, M. L. S. Clínica-escola, Escola da Clínica? Boletim de Psicologia - Sociedade de Psicologia de São Paulo, 42: 96/97, pp. $99-103,1992$.

SILVA, R. C. A Formação em Psicologia para o Trabalho na Saúde Pública. In: Campos, F.C. B. (org.), Psicologia e Saúde-Repensando Práticas. São Paulo: Hucitec, 1992, pp. 25-40.

SPINK, M. J. Assistência à Saúde na Rede Básica. Cadernos FUNDAP São Paulo,1985.

Psicologia da Saúde: a Estruturação de um Novo Campo de Saber. In: Campos, F. C. B. (org.), Psicologia e Saúde- Repensando Práticas. São Paulo, Hucitec, 1992, pp. 11 - 23.

Psicologia Social e Saúde - Práticas, Saberes e Sentidos. Petrópolis: Vozes Editora, 2003.

VILELA, A. M. J. Formar-se Psicólogo, como Ser Livre como um Pássaro (tese). Universidade de São Paulo. São Paulo, 1996.

TELLES, S. R.A, WANDERLEY, K. S.A Importância da Supervisão na Formação do Psicólogo: uma Contribuição da Teoria Winnicottiana. Psikhê - Revista do Centro Universitário FMU, São Paulo, 2000, 5 , 1, pp. $18-23$.

YEHIA, G. Y. AConstrução de Novos Paradigmas no Estágio. Anais do III Encontro Nacional de Supervisores de Estágio na Formação do Psicólogo. Universidade Católica de Pernambuco. Recife, Editora Fasa, pp.41-47, 1996(a)

YEHIA, G. Y. Clínica-escola: Atendimento ao Estagiário ou Atendimento ao Cliente. Coletâneas da ANPEPP. Repensando a Formação do Psicólogo - da Informação à Descoberta. Campinas, Alínea, 1.9, pp.109-118, 1996(b).

\section{Referências}

